\title{
Screening of Potato Lines Including Department Genetic \& National Plant Gene Bank of Iran for Resistance to Early Blight (Alternaria. solani) Using Culture Filtrate Produced by the Fungus
}

\author{
Hamid Reza Mirkarimi $^{1^{*}}$, Ahmad Abasi Moghadam², Javad Mozafari ${ }^{2}$ \\ ${ }^{1}$ Department of Plant breeding, Faculty of Agriculture, Science and Research Branch, Islamic Azad University, Tehran, Iran; \\ ${ }^{2}$ Department of Genetics \& National Plant Gene-Bank, Seed and Plant Improvement Institute, Mahdasht RD, Karaj, Iran. \\ Email: *Rezamirkarimi21@gmail.com
}

Received August $12^{\text {th }}, 2013$; revised September $12^{\text {th }}, 2013$; accepted October $12^{\text {th }}, 2013$

Copyright (C) 2013 Hamid Reza Mirkarimi et al. This is an open access article distributed under the Creative Commons Attribution License, which permits unrestricted use, distribution, and reproduction in any medium, provided the original work is properly cited.

\begin{abstract}
Potato is a plant that can be influenced by early blight disease. Early blight is one of the most destructive plant diseases, especially in the members of solanaceae family. This disease can reduce yield. Experiment design was a factorial randomized complete design to evaluate the isolate pathogenic Alternaria solani in National Plant Gene Bank of Iran, during 2008-2009. This experiment was conducted with three replications, and the factors include test methods and three lines 9506, 10908-05 and 10908-18 with genotypes of Agria, Casmos and Desiree (susceptible) and Delta (resistant control). Analysis of variance table was based on the area under the disease progress curve, indicating the effects of the experimental methods; genotype and their interactions are significant at the $1 \%$ level. In greenhouse evaluation, the symptoms appeared on, the first day. In this method the area under the curve progression was noted in 10 times, but in vitro method, the symptoms of this evaluation appeared on the first or second day. The Evaluation was carried out after inoculation, and was noted 6 times. The results indicate that genotypes and lines are located in four different groups. In this case, line 9506 and Cosmos were quite sensitive to the surface, and Desiree, is located in a sensitive area. Line 1090818 and Agria, located approximately at the level of resistance, and line 10908-05 and Delta, have been resistant surface.
\end{abstract}

Keywords: Screen; Culture Filtrate; Early Blight; Severity

\section{Introduction}

The Potato crop is considered one of the strategic products. According to the Food and Agriculture Organization (2007) we have been producing potatoes up to 321,736 tons in the world, and 5240 tons in Iran [1].

Early blight of potato is the most important foliar diseases [2]. It reduces the level of product yield, and there's a wide world influence [3]. This disease, caused by the $A$. solani fungus, is one of the main diseases of potatoes in tropical climates, especially where potatoes are grown under irrigation [4]. The first reports are relevant to the discussion of $A$. alternata under its synonym ( $A$. tenuis from wheat, $A$. brassicae and $A$. solani of tomato, cabbage) in Iran [5]. The first written report of the disease in Iran goes back to 1977 [6].

*Corresponding author.
Ellis and Martin described the first symptoms on potato leaves. Initially, the symptoms were seen in older and lower leaves $[7,8]$. Based on morphological studies two Alternaria species i.e., A. tenuissima and A. interrupta have been recovered from potato in Iran [9]. The interrelationship between Alternaria species and some substrates had also been recorded and the dangers this can pose to man, as a consumer were highlighted [10-12].

Agria genotype has been reported as susceptible genotypes, isolates of A. solani [13]. The cultivar Desiree is used as a susceptible cultivar and Delta genotypes were reported as resistant genotypes [14]. The specific procedures include the use of low nutrient media, such as PCA, temperature $20^{\circ} \mathrm{C}-25^{\circ} \mathrm{C}$ under a light/dark 8/16 h using a white fluorescent lamp [15-18].

Severity values were plotted against time and the area under the disease progress curve (AUDPC) was calculat- 
ed [19]. Evaluation of susceptibility or resistance exists in potato cultivars with some of these methods [20]. Evaluation of in vitro methods, e.g. spraying the culture filtrated on the plant was introduced first by Locke [21].

\section{Material and Method}

\subsection{Plant Material}

The experiment was conducted in vitro and greenhouse conditions from Genetics and National Plant Gene Bank of Iran during 2008-2009. In this evaluation, the three lines 9506, 10908-05 and 10908-18 with genotypes of Agria, Casmos and Desiree (susceptible) and Delta (resistant control) were evaluated in terms of virulence of pathogenic $A$. solani. The genotypes were maintained on MS medium in the growth chamber conditions $\left(24^{\circ} \mathrm{C} \pm\right.$ $1^{\circ} \mathrm{C}$, a period of $16 \mathrm{~h}$ light and $8 \mathrm{~h}$ dark) for 4 weeks.

\subsection{Spore Production and Inoculation}

All experiments were performed with a single-spore $A$. Solani isolate obtained from the Genetic and National Plant Gene Bank of Iran. For inoculum production, sporulation was induced in 10-day-old $A$. solani were grown in plastic Petri plates on potato dextrose agar (PDA) in continuous (8/16) light/darkness to maximize spore production. Superficial mycelium was removed with $10 \mathrm{ml}$ of sterile distilled water (SDW) and a clean paintbrush and the suspension was discarded. To collect conidia, colonies were scraped with a sterile scalpel and conidia were transferred to a plate containing SDW.

Then suspension with $10^{5}$ conidia/ml were placed in $500 \mathrm{ml}$ glass flasks containing $100 \mathrm{ml}$ of potato dextrose broth (PDB) medium and maintained in the dark at $28^{\circ} \mathrm{C}$ $\pm 2^{\circ} \mathrm{C}$. After 12 days the contents of glass flasks were filtered through the filter $0.2 \mu \mathrm{m}$ and concentrated to centrifuge at $2000-2500 \mathrm{~g}$ for $10-15 \mathrm{~min}$ and the samples are centrifuged at a time.

\subsection{Greenhouse Evaluation}

In this evaluation, the explants were transferred to a greenhouse environment. These plantlets obtained from each single nodal cutting were transplanted into a sterile mixture of peat moss and perlite (2:1 by volume) in a greenhouse. To maintain higher humidity around the cuttings for longer period of time, the trays were covered with plastic covers. After 25 to 30 days, the fungal spore suspension was sprayed using content geysers, and suspension of inoculum was spread uniformly on the leaves.

\subsection{In Vitro Selection by Droplet Using of Culture Filtrate}

Three replications per cultivar were placed whole in vitro plantlets in an $18 \times 2 \mathrm{~cm}$ test tube. The plantlets of potato into test tube were inoculated by droplet of culture filtrate method that the leaflet of potato received a $10 \mu \mathrm{l}$ droplet of the $A$. solani culture filtrate. The test tubes were placed in a growth chamber at a temperature of $20^{\circ} \mathrm{C}-25^{\circ} \mathrm{C}$. The leaflets were rated according to Table $\mathbf{1}$ for reaction to the treatments 1 - 2 days after inoculation until 6 days.

\subsection{In Vitro Selection by Direct Using of Culture Filterate}

Three replications per cultivar were inoculated by placing whole in vitro plantlets in an $18 \times 2 \mathrm{~cm}$ test tube each, containing $5 \mathrm{ml}$ of $A$. solani culture filtrate. This study was conducted using factorial based on completely randomized design (CRD) with 3 replication. The test tubes were placed for $6-7$ days in a growth chamber at $20^{\circ} \mathrm{C}$ $25^{\circ} \mathrm{C}$, with a photosynthetic photon flow density of 100 $\mu \mathrm{E} / \mathrm{m} / \mathrm{s}$ and a day length of $16 \mathrm{~h}$ [20]. During in vitro assay the $A$. solani symptoms appear 1 - 3 days until 6 day. For evaluation of the damage produced by $A$. solani using the scale described in Table $\mathbf{1}$.

\subsection{Pathogenicity Test}

At the end of each of the above tests to ensure the absence of pathogens and other foreign pathogenicity tests, infected leaves after washing with tap water, placed in sterile distilled water for one minute. Then by sodium hypochlorite solution (\%0.5) for 35 seconds and re-sterilization were washed with sterile distilled water. Finally, the pieces are placed on sterile filter paper (for drying) and then transferred to the culture medium [6].

\section{Result}

In these experiments, the symptoms began, the first and second day. Analysis of variance table based on area under the disease progress curve, indicating that the effects of the experimental methods; genotype and their interactions are significant at the $1 \%$ level (Table 2).

\subsection{Greenhouse Evaluation}

In this evaluation, the symptoms appeared, the first day

Table 1. Scale for evaluation of the damage produced by Alternaria species in potato in vitro and greenhouse Plants [22].

\begin{tabular}{cc}
\hline Rating of affectation & Description of symptoms \\
\hline 1 & No lesion development \\
2 & Lesions $<$ 1-mm diameter \\
3 & Lesions 1- to 5-mm diameter \\
4 & Lesions $>$ 5-mm diameter \\
\hline
\end{tabular}


(Figure 1). Area under the curve progression in 10 innings notes, show that 9506 line is located, the highest level (sensitivity), and 10908-05 line is located, at the lowest level (resistance). Cosmos and Desiree genotype are located at the next level, and they are as susceptible genotypes, however, the genotype of Agria is equal to the genotype of Delta, and it is relatively stable. Line of 10908-18, is located in the lower level of the Delta, and it is named as resistant (Table 3).

\subsection{Evaluation of in Vitro-A Drop}

The symptoms of this evaluation appeared the first day (Figure 2). The Evaluation was carried out after inoculation, in 6 times notes. In this evaluation, the 9506 line is equal to the Desiree and the Cosmos, and a susceptible genotype, and lines 10908-05 and 10908-18 are almost at equality with Delta, and it can be considered as resistant. Agria has moderate sensitivity, and it is not quite as susceptible genotypes (Table 4).

\subsection{In Vitro Evaluation of Direct}

In this evaluation, the symptoms appeared the second day (Figure 3). The evaluation was carried out after inoculation, notes of in 6 times. Cosmos genotype was equal in 9506 line and Desiree, and it is a sensitive genotype. 10908-05 and 10908-18 lines, are at lower levels of Agria, and almost equal to the data, which can be named as resistant. Also, Agria had moderate sensitivity, and it is not quite as susceptible genotypes (Table 5).

Table 2. Analysis of variance assessed in vitro (drop-Direct) and greenhouse conditions for pathogenic $A$. solani.

\begin{tabular}{cccc}
\hline Source & df & Mean Square & F \\
\hline Method & 2 & 15315.965 & $261669.373^{* *}$ \\
Genotype & 6 & 146.039 & $2495.045^{* *}$ \\
Method × genotype & 12 & 54.581 & $932.503^{* *}$ \\
Error & 42 & 0.059 & \\
Total & 62 & & \\
\hline
\end{tabular}

Table 3. Comparison mean of potato genotypes with AUDPC by Tukey at $5 \%$ level (greenhouse method).

\begin{tabular}{ccc}
\hline Genotype & \multicolumn{3}{c}{ AUDPC Mean } \\
\hline 10908-05 line & 49.00 & $\mathrm{f}$ \\
10908-18 line & 51.66 & $\mathrm{e}$ \\
Delta & 56.16 & $\mathrm{~d}$ \\
Agria & 56.50 & $\mathrm{~d}$ \\
Desiree & 65.16 & $\mathrm{c}$ \\
Casmos & 70.00 & $\mathrm{~b}$ \\
9506 line & 71.00 & $\mathrm{a}$ \\
\hline
\end{tabular}

Table 4. Comparison mean of potato genotypes with AUDPC by Tukey at $5 \%$ level (in vitro method-drop).

\begin{tabular}{ccc}
\hline Genotype & \multicolumn{2}{c}{ AUDPC Mean } \\
\hline Delta & 12.66 & d \\
10908-05 line & 15.08 & c \\
10908-18 line & 15.25 & bc \\
Agria & 15.58 & b \\
9506 line & 17.50 & a \\
Desiree & 17.75 & a \\
Casmos & 17.91 & a \\
\hline
\end{tabular}

Table 5. Comparison mean of potato genotypes with AUDPC by Tukey at $5 \%$ level (in vitro method-direct).

\begin{tabular}{ccc}
\hline Genotype & \multicolumn{2}{c}{ AUDPC Mean } \\
\hline Delta & 7.83 & e \\
10908-05 line & 8.58 & d \\
10908-18 line & 10.08 & c \\
Agria & 11.25 & b \\
Desiree & 12.50 & a \\
9506 line & 12.50 & a \\
Casmos & 12.66 & a \\
\hline
\end{tabular}
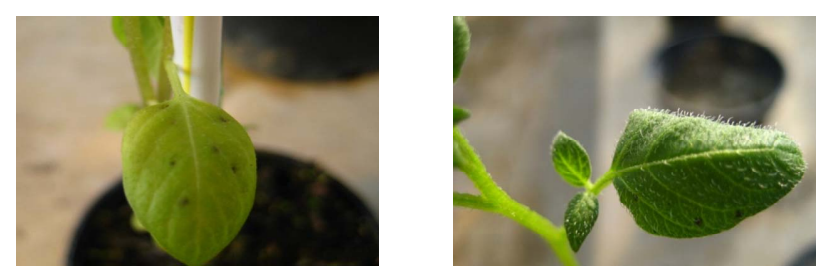

Figure 1. Greenhouse evaluation-View chlorotic and necrotic spots caused by pathogenic $A$. solani.

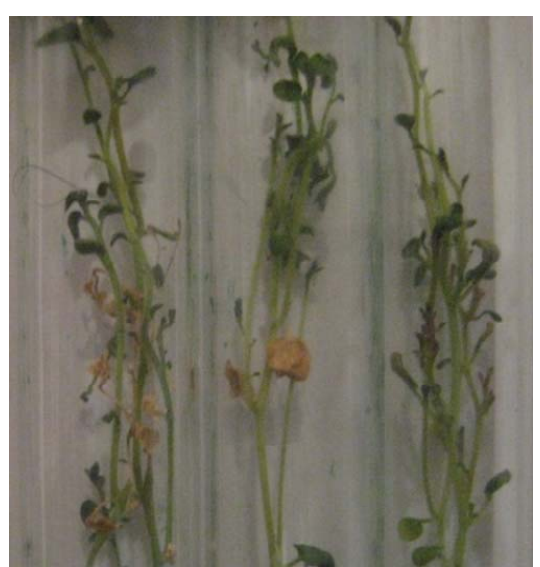

Figure 2. In vitro evaluation of drop method-View necrosis and leaf chlorosis.

\subsection{Correlations between Traits}

The correlation table shows that there is a high correla- 
tion between test methods. The highest correlation is between the two in vitro methods direct and drop. The correlation between these methods is positive. Correlation indicates that evaluation of each of these methods, have similar results together, and can be evaluated; use either of these methods separately (Table 6).

\subsection{Cluster Analysis}

The results of cluster analysis indicate that genotypes and lines are located in four different groups. In this case, line 9506 and Cosmos were quite sensitive to the surface, and Desiree, is located in a sensitive area. Line 10908-18 and Agria, located approximately at the level of resistance, and line 10908-05 and Delta, have been resistant surface (Figure 4).

\section{Discussion}

Mirkarimi et al., showed that the Cosmos are more sensitive genotypes than isolates $A$. tenuissima, and our results also indicate that this is a sensitive genotype [4].

Dita Rodriguez et al. reported that the susceptible genotype Desiree, genotype Delta is resistant. These findings are consistent with our results [20].

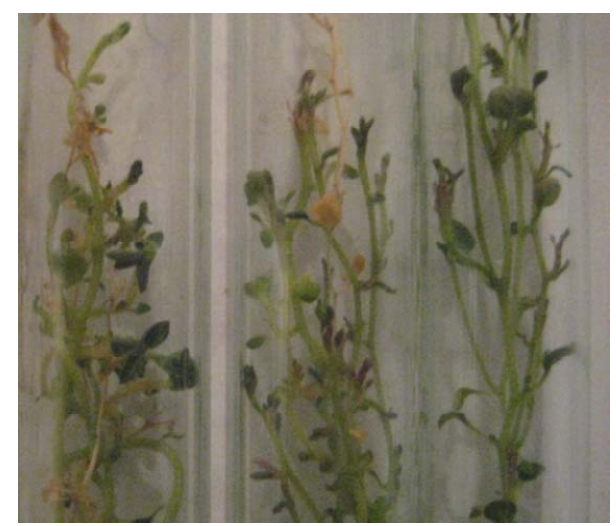

Figure 3. In vitro evaluation of direct method-View necrosis and leaf chlorosis.

Table 6. Correlation between in vitro and greenhouse methods based on area under the disease progress curve.

\begin{tabular}{llrrr}
\hline & & greenhouse & \multicolumn{1}{l}{ drop } & \multicolumn{1}{c}{ direct } \\
\hline \multirow{2}{*}{ Greenhouse } & Pearson Correlation & 1 & $0.747^{* *}$ & $0.817^{* *}$ \\
& Sig. (2-tailed) & & 0.000 & 0.000 \\
\multirow{5}{*}{ Drop } & $\mathrm{N}$ & 21 & 21 & 21 \\
& Pearson Correlation & $0.747^{* *}$ & 1 & $0.941^{* *}$ \\
& Sig. (2-tailed) & 0.000 & & 0.000 \\
\multirow{5}{*}{ Direct } & $\mathrm{N}$ & 21 & 21 & 21 \\
& Pearson Correlation & $0.817^{* *}$ & $0.941^{* *}$ & 1 \\
& Sig. (2-tailed) & 0.000 & 0.000 & \\
& $\mathrm{~N}$ & 21 & 21 & 21 \\
\hline
\end{tabular}

*Correlation is significant at the 0.05 level. ${ }^{* *}$ Correlation is significant at the 0.01 level.

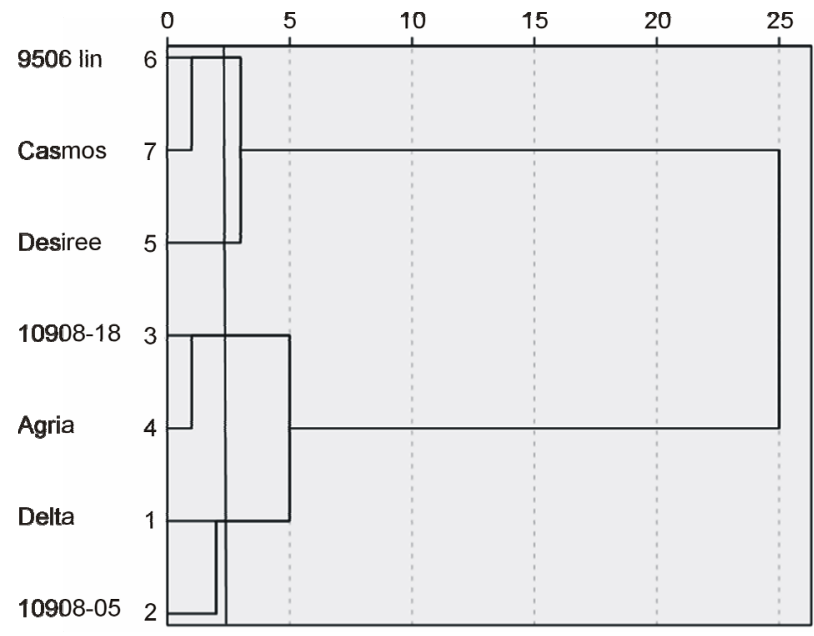

Figure 4. Cluster analysis based on two in vitro conditions and greenhouse methods.

In other studies, Nasr Esfahani, stated that shortening is a sensitive genotype, and the evaluation shows that this genotype, has been resistant surface. These results could be due to the effects of different fungal isolates, and better yet, researchers have not used it as a susceptible genotype in our experiments [13].

Finding resistant or immune genotypes to the disease, is highly effective in controlling it. Therefore, finding the resistant genotypes could be considered an advantage in the cases of crop cultivars [17]. Based on this test, line 05-10908, can be considered as a resistant line, and it can be introduced to farmers, after physiological and agronomic tests.

\section{Acknowledgements}

This experiment, we would like to thank the officials and employees of the Department of Genetics and National Plant Gene Bank of Iran. Also, we would like to thank faculty Department of Plant Breeding and Biotechnology, Science and Research Branch, Islamic Azad University, Tehran.

\section{REFERENCES}

[1] Anonymous, “Agricultural Statistics,” Vol. 1. 2007-08 Cropping Seasons. Ministry of Jihad-e-Agriculture, Tehran, 2009.

[2] H. Shahbazi, H. Aminian, N. Sahebani and D. Halterman, "Effect of Alternaria solani Exudates on Resistant and Susceptible Potato Cultivars from Two Different Pathogen Isolates,” Plant Pathological Journal, Vol. 27, No. 1, 2011, pp. 14-19. http://dx.doi.org/10.5423/PPJ.2011.27.1.014

[3] S. Taheri Ardestani, B. Sharifnabi, R. Zare and A. Abbasi moghaddam, "Alternaria Species Associated with Potato 
Early Blight in Iran,” Asian Mycology Congress and International Marine \& Freshwater Mycology Symposium, 2-6 December 2007, pp. 266-216.

[4] H. R. Mirkarimi, A. Abasimoghadam and J. Mozafari, "Evaluation of Disease Resistance Potential of Seven Potato Genotypes against Early Blight Caused by Alternaria tenuissima under Greenhouse Conditions,” Journal of Experimental Biology and Agricultural Sciences, Vol. 1, No. 3, 2013, pp. 191-196.

[5] E. Esfandiari, "Troixieme Liste des Fungi Ramasses en Iran,” Entomologie et Phytopathologie Appliquees, Vol. 8, 1948, pp. 1-12.

[6] S. Taheri Ardestani, B. Sharifnabi, R. Zare and A. Abbasi moghaddam, "New Alternaria Species Associated with Potato Leaf Spot in Various Potato Growing Region of Iran,” Journal of Plant Diseases (Iran), Vol. 45, No. 4, 2009, pp. 301-308.

[7] J. B. Ellis and G. B. Martin, "Macrosporium solani E\&M,” American Naturalist, Vol. 16, 1982, p. 1003.

[8] J. W. Pscheidt, "Epidemiology and Control of Potato Early Blight, Caused by Alternaria solani,” PhD Thesis, Van der Waals et al., Review of Early Blight of Potato 101, University of Wisconsin-Madison.

[9] S. Taheri Ardestani, B. Sharifnabi, R. Zare and A. Abbasi Moghaddam, "Introduce Two New Isolate of Alternaria Species in Iran,” 18th Congress of Plant Pathology, Hamedan, 2008.

[10] B. Anderson and R. G. Roberts, "Towards a Polyphasic and Predictive Taxonomy for Small Spored Alternaria,” Proceedings of the 7th International Mycological Congress, Oslo, 11-17 August 2002, p. 72.

[11] B. J. Christ and K. G. V. Haynes, "Inheritance to Early Blight Disease in a Diploid Potato Population," Plant Breeding, Vol. 120, 2001, pp. 169-172. http://dx.doi.org/10.1046/j.1439-0523.2001.00565.x

[12] N. Veitia, M. A. Dita, L. Garcia, L. Herrera, I. Bermudez, M. Acosta, J. Clavero, P. Orellana, C. Romero and L. Garcia, "Use of Tissue Culture and the Mutagenesis in Vitro for the Improvement of the Resistance to Alternaria solani (Solanum tuberosum Lin.), to varDesiree,” 2001.

[13] M. Nasr Esfehani, "Evaluation of Early Blight of Potato
Disease in Friden,” Annual Report Isfahan Plant Pathology, 2004, pp. 256-276.

[14] M. A. Dita Rodriguez, S. H. Brommonschenkel, K. Matsuoka and E. S. G. Mizubuti, "Components of Resistance to Early Blight in Four Potato Cultivars: Effect of Leaf Position," Journal of Phytopathoogylogy, Vol. 154, 2006, pp. 230-235. http://dx.doi.org/10.1111/j.1439-0434.2006.01089.x

[15] B. Anderson, E. Kroger and R. G. Roberts, "Chemical and Morphological Segregation of Alternaria alternata, A. gaisen and A. longipes,” Mycological Research, Vol. 105, 2001, pp. 291-299. http://dx.doi.org/10.1017/S0953756201003446

[16] B. Andersen, E. Kroger and R. G. Roberts, "Chemical and Morphological Segregation of Alternaria arborescense, A. infectoria and A. tenuissima Species Groups," Mycological Research, Vol. 106, 2002, pp. 170-182. http://dx.doi.org/10.1017/S0953756201005263

[17] F. M. Dugan and T. L. Peever, "Morphological and Cultural Differentiation of Described Species of Alternaria from Poaceae,” Mycotaxon, Vol. 83, 2002, pp. 229-264.

[18] R. G. Roberts, “Alternaria alternata Ubiquitous or Commonly Misidentified,” Phytopathology, Vol. 92, No. S76.

[19] G. Shaner and R. E. Finney, "The Effect of Nitrogen Fertilization in the Expression of Slow-Mildewing Resistance in Knox Wheat,” Phytopathology, Vol. 67, 1977, pp. 1051-1056. http://dx.doi.org/10.1094/Phyto-67-1051

[20] N. V. Rodriguez, B. Kowalski, L. G. Rodriguez, B. Caraballoso, M. A. Suarez, P. O. Perez, C. R. Quintana, N. Gonzalez and R. Q. Ramos, "In Vitro and ex Vitro Selection of Potato Plantlets for Resistance to Early Blight," Journal of Phytopathology, Vol. 155, 2004, pp. 582-586. http://dx.doi.org/10.1111/j.1439-0434.2007.01282.x

[21] S. B. Locke, "A Method for Measuring Resistance to Defoliation Diseases in Tomato and Other Lycopersicon Species,” Phytopathology, Vol. 38, 1948, pp. 937-942.

[22] B. M. Pryor and T. J. Michailides, "Morphological, Pathogenic, and Molecular Characterization of Alternaria Isolates Associated with Alternaria Late Blight of Pistachio," Phytopathology, 2002, pp. 406-416. http://dx.doi.org/10.1094/PHYTO.2002.92.4.406 